\title{
La homofonía en el aprendizaje de lenguas: el caso del español. Implicaciones didácticas
}

\author{
Amando López VAlero \\ EduARdo EnCABo FERNÁNDEZ \\ Universidad de Murcia \\ ISABEL JÉREZ MARTÍNEZ \\ Universidad de Castilla-La Mancha
}

Recibido: 31 de enero de 2012 / Aceptado: 6 de junio de 2013

ISSN: $1697-7467$

\begin{abstract}
RESUMEN: En esta aportación reflexionamos acerca de los términos homófonos como componentes de la lengua española. Deseamos incidir en la dimensión ortográfica y la relación con los mencionados términos. Tras realizar un repaso de aquellos homófonos que son paradigmáticos en la lengua española, acotando su uso cotidiano o dificultad, es nuestro deseo establecer las bases filosóficas de intervención didáctica en lo que respecta a estos elementos de la lengua española, con la finalidad de que tanto usuarios noveles como nativos tomen conciencia de los mismos y de que el profesorado tenga más clara la intervención didáctica relacionada con las palabras homófonas.
\end{abstract}

Palabras clave: Ortografía, Gramática, Lengua española, Enseñanza de la lengua

\section{Homophony in Language Teaching: Teaching Implications Within the Spanish} Context

\begin{abstract}
In this contribution we reflect on the homophones as elements of the Spanish language. We intend to highlight the spelling dimension and its relationship to that precise kind of words. After a review of the paradigmatic homophones in Spanish language, we pretend to establish the bases for a didactic purpose with a clear intention of helping teachers to realise the importance of this topic in the teaching of language.
\end{abstract}

Keywords: Ortography, Grammar, Spanish language, Teaching of language

\section{INTRODUCCIÓN}

En este estudio se pretende mostrar una profunda y documentada reflexión acerca de la gramática española, tratando de incidir en uno de los aspectos que históricamente ha resultado problemático para los usuarios nativos y extranjeros de dicha lengua: el uso de los términos homófonos. Este aspecto recurrente en diversas lenguas (i.e. lengua inglesa) supone un reto para el hablante a la hora de transponer sus conocimientos a la lengua escrita. Ni siquiera los nativos dominan perfectamente los aspectos homófonos de su lengua, cometiendo errores que motivan incorrección gramatical. El intento de hacer correspondencias directas entre fonemas y grafemas motiva que no se posea un conocimiento exhaustivo de la lengua, y sobre todo, que no se proceda a realizar la necesaria reflexión gramatical, siendo las imperfecciones en la utilización de la lengua el resultado más evidente. 
Actualmente, en el globalizado entorno económico-político-social, la corrección en el uso de la lengua no es una de las dimensiones más logradas ya que muchos de los estímulos sociales que se reciben por parte de los medios de comunicación de masas, incluyen los mencionados errores, que se expanden de una manera vertiginosa, generando un debate social que tiende al uso o no de la rigurosidad. Preguntas claras surgen de esta situación: ¿es necesaria la norma en el uso de la lengua española o se puede ser flexible amparándonos en la importancia de la comunicación y lo valioso del entendimiento?, ¿la desventaja didáctica es explícita con respecto a la influencia de los medios de comunicación? Y una tercera pregunta nos preocupa: ¿conocen los docentes la gramática española?

Por ello, en nuestra aportación hemos tenido que plantear una cuestión recurrente en las últimas décadas, ¿se enseña lengua o se enseña gramática? Recordemos la aportación de Henry Widdowson (1978: 2):

When we acquire a language we do not only learn how to compose and comprehend correct sentences as isolated linguistic units of random occurrence; we also learn how to use sentences appropriately to achieve a communicative purpose. We are not just walking grammars.

Cuando adquirimos una lengua no aprendemos únicamente cómo componer y comprender oraciones correctamente considerando éstas como unidades lingüísticas aisladas de frecuencia aleatoria; también aprendemos cómo utilizar las oraciones adecuadamente para conseguir un propósito comunicativo. No somos solamente gramáticas andantes (Traducción de los autores)

Los extremos aplicados como respuesta a tal pregunta generan libertinaje en el uso de la lengua o bien generan extrema rectitud. Así, En la línea planteada por Cassany (2006), Pérez Esteve y Zayas (2007), Camps (2009), Lomas (2009), Isla (2012) o Lomas y Tusón (2012), el profesorado debería procurar aproximarse al enfoque comunicativo de la enseñanza de la lengua sin que por ello, se deba abandonar el rigor normativo de la lengua española. Pensemos que el docente es la referencia clave para que el alumnado se sienta motivado a respetar las normas de la lengua, ya que si no existe una guía solvente al respecto, se generará un desinterés por la utilización del acervo lingüístico, y los discursos cada vez serán más deslavazados, tanto en su profundidad como en su aspecto estético.

Es evidente que las dificultades existen y por ello, planteamos en este texto la reflexión didáctica acerca de los homófonos en lengua española, como uno de los elementos que se muestra como obstáculo a superar si se desea estar en la senda de un uso correcto de la lengua. Como veremos más adelante, tendremos que afrontar reflexiones relacionadas con la pertinencia de los mismos y también observaremos que existen homófonos paradigmáticos en la lengua española que siguen ocasionando dificultades a los usuarios nativos o a los que se aproximan por primera vez a la lengua española.

\section{LA hOMOFONía COMO ASPECTO PARTICULAR de LA LENGUA ESPAÑola}

Aportaciones previas como las de Martín (2003), Callau (2005) o Waluch y Vercher (2007) nos alertan de la presencia e importancia de los homófonos, además de aportar pautas 
para su tratamiento, pero al mismo tiempo permiten nuestra reflexión relativa a los estudios relacionados y es que, aunque existen [véase, Dalbor (1980); Techner (2000); Hammond (2001); Guitart (2004); Schwegler y Kempf (2007), Morgan (2009), Buenafuentes y Sánchez (2012) o Gómez Torrego (2012)] no es un tópico acerca del cual existan infinitud de estudios y mucho menos relacionados con el ámbito educativo.

El acceso a la lengua española y concretamente cuando intentamos realizar planteamientos didácticos para hacer más sencillo y plausible su aprendizaje, trae como consecuencia encontrarnos con la dificultad de los pares de letras que en la mencionada lengua derivan en la homofonía. Así, por ejemplo, la /b/ y la /v/, la /c/ y la /z/, la /g/ y la /j/, como por supuesto, la hache, suponen un desafío particular ya que, en muchas ocasiones se incluyen en palabras homófonos que derivan en un problema de duda a la hora de escribir la palabra que se ha pronunciado.

En este sentido, el planteamiento ortográfico de grandes autores como Antonio de Nebrija se orientaba hacia la transposición directa entre la pronunciación y la escritura de las palabras. Retomar dicha situación motivaría toda una transformación de las estructuras de la lengua que actualmente conocemos y usamos. No es el único autor que ha razonado de dicha forma, ya que Miguel de Unamuno en su novela Niebla, ya explicitaba el razonamiento de la siguiente manera:

Así tenemos que escribir como pronunciamos y pronunciar como escribimos, pues, de otra manera, en vano fueron halladas las letras". También, Unamuno planteaba en su obra Niebla, una reflexión al respecto: "hay que escribir el castellano con ortografía fonética, ¡Nada de ces! ¡Guerra a la c! Za, ze, zi, zo, zu con zeta, y ka, ke, ki, ko, ku con ka. ¡Y fuera las haches! ¡La hache es el absurdo, la reacción, la autoridad, la Edad Media, el retroceso!, ¡Guerra a la hache! (Niebla. Página 148)

¿Estamos en condiciones de retornar a los planteamientos de Unamuno y escribir tal y como pronunciamos? ¿No es acaso esta situación la que es llevada a cabo por los usuarios de teléfonos móviles cuando por mor de la economía hacen uso de un código particular que no se ajusta al uso normativo de la lengua española? Recientemente, la Real Academia en su publicación Ortografía de la lengua española (2010) orienta su edición hacia unas características particulares que tienden a un enfoque comunicativo. Por ello, aborda con minuciosidad la mayoría de los problemas ortográficos que se presentan al hablante en los diferentes ámbitos de la norma escrita. Por ejemplo, uso de las letras, puntuación o mayúsculas y minúsculas. Además, intenta determinar los fundamentos, principios e ideales teóricos en los que se basan las prescripciones establecidas para la correcta escritura a lo largo del tiempo. Para ello, procura explicar las relaciones que mantiene la ortografía con otras ramas de la lingüística, como la fonología, la morfología y la sintaxis. Este planteamiento implica que la lengua se relativice en lo que concierne a su planteamiento estructural, esto es, la búsqueda de lo comunicativo constriñe menos al usuario y de ese modo, ya no es tan inasequible el acceso a la lengua por parte de nativos y de hablantes extranjeros. Recordemos la univocidad de determinados sonidos como /b/ y /v/ cuya pronunciación no se distingue. En el caso que nos atañe referido a la homofonía, únicamente en la forma escrita serían relevantes para el aprendizaje. 
La homofonía sigue formando parte de esa prescripción y explicación de la lengua española. Con respecto de la misma, nos indica De la Cruz (1999: 61) que,

Este fenómeno parece tener mucha más fuerza en inglés que en castellano, ya que la lengua inglesa, debido a la falta de adecuación que presenta entre grafía y sonido hace que exista gran número de parejas homófonas. Así, mientras en español se documenta algún texto en el que se ha empleado este recurso, en inglés encontramos todo tipo de composiciones, desde pasajes literarios a chistes, adivinanzas u otros.

De este modo, indicaríamos que se atribuye este fenómeno a una palabra: que suena de igual modo que otra, pero que difiere en el significado; por ejemplo: tubo y tuvo, huno y uno. En este sentido, las sensibles modificaciones ortográficas que realiza la Real Academia tienen que ver con, la exclusión de los dígrafos $c h$ y $l l$ del abecedario, este hecho no interviene directamente en la situación homófona ya que lo que hace es reforzar la eliminación distintiva de la correspondencia fonema-grafema. Antaño, la pronunciación de la /11/ motivaba que no hubiese confusión a la hora de transponer por ejemplo las formas /haya/ y /halla/ pero ante la eliminación del dígrafo /11/ ya no se puede producir tal distinción. Sí se produce una ayuda ante, la sustitución, por grafías propias del español, de la $q$ etimológica con valor fónico independiente en aquellos extranjerismos y latinismos plenamente adaptados al español (quorum > cuórum). Esta situación evita que la persona dude ante la escritura de dichos términos aunque invita al olvido de las raíces latinas, ya que las personas que no quieran profundizar en el conocimiento etimológico, no tendrán necesidad ni obligación de hacerlo. Otras incorporaciones en la citada ortografía básica, inciden en la explicación de la diferenciación de términos que tienen que ver con la homofonía. Así, A ver/haber, Hallal haya/aya, Echo, echa, echas/hecho, hecha, hechas, son explicados de una manera explícita, poniendo de manifiesto las dificultades que los usuarios de la lengua española muestran.

Comprobamos pues, que si bien la lengua española no es tan prolífica en términos homófonos como lo pueda ser la lengua inglesa, sí que abundan situaciones que son generadas por el uso de este tipo de palabras y en las que se tiende al error. En ocasiones, estos fallos son producto del uso constante de determinadas formas y la generalización de las mismas. Por ejemplo, echar/hecho, el uso desmedido de la segunda forma provoca que no haya discriminación y que se cometan errores como hechar las cartas. Fijémonos que es un error completamente ortográfico, ya que en el discurso oral pasa desapercibido.

\section{3. ¿Es NeCESARIA LA DISTINCIÓN HOMÓFONA PARA EL DESARROLlo DE LA LENGUA ESPAÑOLA?}

El ejemplo con el que finalizábamos la sección anterior motiva la redacción de este epígrafe ya que, desde una óptica exclusivamente comunicativa, queda en entredicho la necesidad de estas distinciones generadas por la lengua española. Nos indica Sarmiento (2010: 10) que:

con la reforma ortográfica (2010), se reaviva la vieja controversia entre los partidarios de la simplificación y adaptación a la pronunciación, denominada ortografía 
fonética, y los seguidores del criterio etimológico y del uso. Los primeros abogan por simplificarla eliminando del alfabeto letras como $h, v, q, x, k$ por no significativas o duplicadas; los segundos, aun abrazando el principio fonético de escribir como se habla, exigen que este sea ley consentida por todos. Como dijo el latino Horacio, el uso es el árbitro y señor de las lenguas.

Desde nuestra perspectiva, el problema reside en una cuestión cultural. Optar únicamente por la ortografía fonética supone "desmontar" un complejo entramado cultural que se expande desde formularios meramente administrativos hasta textos literarios que forman parte del acervo cultural de la sociedad. Es cierto que muchas veces el hablante se puede plantear la necesidad de la inclusión o no de una hache, o la propia distinción que se puede producir en una familia donde alguien quiera apellidarse Giménez con /g/ y otro familiar quiera presentar ese mismo apellido Jiménez con $/ \mathrm{j} /$, pero lógicamente, desde el punto de vista cultural, dichas situaciones siempre estarán justificadas e incardinadas por una justificación social y del mecanismo cultural.

Por consiguiente, una de las grandes trabas con las que se encuentra el aparato didáctico tiene que ver con la toma de conciencia de dichas situaciones por parte del usuario de la lengua, es decir, cómo procurar que ese hablante comprenda la norma establecida, y sobre todo, que pueda ser capaz de poder aplicarla. Para nuevos hablantes, obviamente el hecho de ser capaces de saber distinguir las situaciones relacionadas con palabras homófonas en lengua española va a ser complicado, pero para los nativos no debería ser algo lejano.

Revisando las orientaciones de la Real Academia, apreciamos que no se renuncia a la situación ortográfica que tiene que ver con la utilización de palabras homófonas sino que se trata de allanar el camino hacia el buen uso de la lengua española por parte de los hablantes. Pese a esta situación, las palabras homófonas continúan suponiendo un problema en el aprendizaje de la lengua, ya que las condiciones sociales y educativas no crean un espacio idóneo para que la persona que se aproxima a la lengua española procure imprimir el rigor necesario a su interacción con los componentes lingüísticos. Algunas de las claves de esos problemas de adquisición idónea de la lengua española tienen que ver con la permanencia, en muchos casos hegemónica, de modelos lingüísticos anclados en el estructuralismo que no permiten al usuario razonar y sobre todo reflexionar acerca de los términos que utilizar y sobre todo, sobre por qué lo hace.

De igual modo, el libertinaje con el cual se asimila el modelo comunicativo, hace que existan docentes que interpretan que dicho enfoque debe no dar tanta importancia a la norma. De esta manera, se genera un claro conflicto ya que los receptores de los aprendizajes que van a ser usuarios de la lengua, no van a tener las herramientas adecuadas para la mencionada utilización. Otro aspecto clave tiene que ver con la poca promoción social y educativa que se realiza del vocabulario. Esto es, el potencial lingüístico de las personas en lo que respecta a su dominio léxico no es todo lo satisfactorio que debería, cuestión que enlaza directamente con los niveles de lectura. Si la utilización de palabras que hacen las personas es limitada, lógicamente las dificultades se multiplican. Y en el caso de los términos homófonos, las personas no poseen los recursos adecuados al no haber ejercitado lo suficiente su reflexión y dominio de la lengua española. Puede ser el ejemplo de hatajo y atajo. El uso menos frecuente del primer término provocará que las personas opten por escribir la palabra casi siempre sin hache aunque el contexto esté referido a la palabra. Otra 
manifestación donde podemos ver la dificultad homófona es ojear y hojear. Únicamente alguien que esté versado en la lengua española podrá distinguir sin dudas, cuál es el término correcto para el contexto que se le plantee.

Por consiguiente, en este texto resolvemos la cuestión, afirmando que sí es preciso mantener las cuestiones relacionadas con los homófonos en la lengua española, tomando como referencia el entramado sociocultural, que es complicado desquebrajar. Así pues, la enseñanza será la clave para poder mejorar la competencia de las personas ante el manejo de las palabras homófonas.

\section{LA REFLEXIÓN ACERCA DE LA GRAMÁtiCA ESPAÑOLA: LA ORTOGRAFía}

La lengua española cuyas raíces quedan hundidas en el latín y el posterior mestizaje con la cultura presenta en su gramática claras señas de identidad que tienen que ser aprendidas y dominadas por aquellas personas que quieren incorporar el uso de la forma española a su discurso. Conocemos que la lengua española ha sufrido a lo largo de su historia varias y profundas reformas. Recordemos, las aportaciones de Alfonso X el Sabio o la Ortografía de Nebrija (1517), "donde la regularización del sistema ortográfico, guiada por el ideal fonetista de que a cada sonido le correspondiera una sola letra, facilitó mucho el hecho de que el castellano se erigiera en la lengua internacional de entonces con mayor difusión por Europa, por América y por otros confines" (Sarmiento, 2010: 9). La siguiente reforma auspiciada por la Real Academia fue la más técnica. Publicada en 1815, gran parte de su contenido se mantiene vigente. Propugnando la unidad del Hispanismo, asistimos en la actualidad a la puesta en marcha de la última reforma ortográfica.

Llegados a este punto temporal, el debate acerca de la presencia de homófonos en la lengua española no está superado, ya que seguimos encontrando múltiples manifestaciones que hacen dudar al usuario con respecto de la forma correcta que debe utilizar a la hora de escribir el término al que verbalmente se ha referido. Otra vuelta de tuerca se produce si reflexionamos acerca del contexto en el cual se produce la escritura de homófonos, es decir, las condiciones sociales han variado y los soportes no son los mismos. Nos indica Gómez (2007: 157) que "La ortografía y el mismo alfabeto no son más que una convención gráfica condicionada por el soporte en el que se produce el texto escrito". Desde este punto de vista, la revolución social se impondría a la norma y se iría imponiendo en los usos, un ejemplo claro es el que tiene que ver con los códigos que se incluyen en la mensajería de los móviles, o en las formas de comunicarse teniendo como referencia los entornos virtuales que generan los usos de chats o de programas concretos relacionados con lo tecnológico. En la línea de lo aportado por el citado investigador, se encuentran las aportaciones de Daniel Cassany $(2003,2012)$, quien coincide en que los cambios sociales, sin duda, tienen relación con la forma de escribir de las personas. A tenor de dicha situación, una mayor concordancia tendría que acontecer entre normativa lingüística y los aludidos cambios.

Siendo conscientes de la arbitrariedad de lo lingüístico y de la no inmutabilidad del mismo, también advertimos de la lentitud de los cambios y de la necesidad temporal de la sociedad para asimilarlos (baste el ejemplo del término guion, cuya necesidad de tilde ha sido eximida por la Real Academia y que motiva en ciertos usuarios una reacción de rebeldía queriendo usar la anterior manifestación; un ejemplo de evolución que tiene que 
ver con esta situación, lo hallamos en la forma verbal fué cuya tilde en la actualidad no es necesaria; el tiempo transcurrido ha hecho que se normalice la situación, pero no ha sido una cuestión de breve tiempo sino de años). Por tanto, tendremos que aguardar para comprobar si la influencia tecnológica motiva un cambio trascendente en el código.

En el difícil equilibrio de lo normativo y del uso de la lengua, nos indica Pato (2008: 18) que, "desde el modelo de Gramaticalización, el cambio lingüístico es visto como innovación y recreación. Todo cambio conlleva un desajuste en el sistema, pero no necesariamente una erosión en el mismo; y ello es debido a que los hablantes "acuerdan" y "crean", por y para fines comunicativos, el significado de sus producciones". Retomamos la concepción arbitraria de la lengua, pero aplicado este hecho a la cuestión homófona no resuelve el problema, ya que, cuando se ha planteado esta situación y su posible transformación en la lengua española, se ha optado por proponer modelos enmarañados y confusos en los que se confundían letras (por ejemplo, /b/ y /v/) y no había armonía ni claridad en los planteamientos.

Retomando la alusión previa realizada de los docentes, para el profesorado es complicado generar una solución a esta situación, ya que no hay unanimidad en los puntos de vista que con respecto de la misma se plantean. Si bien se está de acuerdo con los errores ortográficos, no se llega a un consenso relativo a la gravedad de los mismos, localizando posturas más estrictas y otras relacionadas con el libertinaje. Añadiendo a esta situación que, en ocasiones, es el profesorado quien no reconoce la norma en el uso de la lengua española. Cobran importancia en este caso investigaciones como las de Carratalá (1997) o Camps (2006) cuando inciden en la importancia de la enseñanza de la ortografía.

\section{HOMÓFONOS PARADIGMÁTICOS: LUCES Y SOMBRAS}

Realizar un recorrido exhaustivo analizando todas las palabras homófonas de la lengua española y todos los grupos que éstas pueden generar, los cuales a su vez también pueden ser objeto de esa homofonía sería un trabajo ingente. Por esa razón, es nuestro deseo comentar una muestra de los aludidos términos, incidiendo en aquellos que por su menor uso pueden provocar errores en el usuario y por ende, incorrección gramatical, induciéndolo al dominio de un código restringido en lugar de un código elaborado (conceptos desarrollados por Bernstein, 1988a y 1988b).

Tabla número uno: tipología homofónica

\begin{tabular}{|l|l|}
\hline Manifestación del homófono & Ejemplo \\
\hline$/ \mathrm{v} / \mathrm{y} / \mathrm{b} /$ & tubo/tuvo o rebelarse/revelarse \\
\hline$/ \mathrm{g} / \mathrm{y} / \mathrm{j} /$ & Vegete (de vegetar)/vejete (de viejo) \\
\hline$/ \mathrm{h} /$ & Hecho (de hacer)/echo (de echar) \\
\hline$/ \mathrm{ll} / \mathrm{e} / \mathrm{y} /$ & arrollo (de arrollar)/arroyo \\
\hline$/ \mathrm{s} / \mathrm{y} / \mathrm{x} /$ & Espirar/expirar \\
\hline
\end{tabular}


Agrupando los tipos de homófonos en función de las letras del alfabeto español, hallamos que el primero de ellos estaría ubicado en la distinción $/ \mathrm{v} / \mathrm{y} / \mathrm{b} /$, en el mismo encontramos distinciones sencillas como Baca/vaca o Botar/votar pero otros casos como barón/varón, combino/convino, tubo/tuvo, y sobre todo, rebelarse/revelarse y recabar/recavar, originan dudas en el hablante. Centrémonos en estos dos últimos casos. Es frecuente que nativos españoles puedan mostrar dificultades en su uso, y que ante la duda en el momento de escribir el término opten por el erróneo para el contexto que se les plantea. Curiosamente, tienden a utilizar el que se corresponde con su uso más frecuente (rebelarse de rebelión y recavar del verbo cavar), lo que corrobora la situación referida a la disminución de vocabulario y la restricción grupal que en ese uso se realiza. Al no tener la necesidad de expandir su léxico se produce una recuperación de los recursos más cercanos y ellos son los que producen el error.

La siguiente letra que origina múltiples conflictos al usuario en el momento de utilizar los términos adecuados en lengua española es la hache. Hemos comentado en apartados previos el ejemplo que supone hatajo/atajo, donde el mayor conocimiento de la segunda palabra supondría la tendencia para su uso. Sucede algo similar con otro comentado ejemplo, hojear/ojear, en el que la expansión del segundo término, su asociación con la palabra ojo, y la poca reflexión sobre la lengua que acontece, motiva que existan errores cuando se plantea la situación. Pero uno de los casos donde más errores suele cometer el usuario, precisamente por la poca reflexión sobre la lengua y por el no dominio de la misma, proviene de los términos Hecho (de hacer)/echo (de echar) o en el caso de deshecho (de deshacer)/desecho (de desechar). En ambos casos suele suceder que se "abusa" de la hache y no se distingue entre las situaciones planteadas, aconteciendo el error de manera irreversible.

La eliminación del dígrafo /11/ no implica que no continúen existiendo dudas en el hablante a la hora de utilizar determinadas palabras en lengua española. Así, arrollo (de arrollar)/arroyo es una de las parejas que no son fácilmente detectables por alguien que no domina la lengua o que no es cuidadoso en el uso. Sucede lo mismo con los términos Rallar/rayar, y, sin duda, uno de los grandes errores de uso de los hablantes relacionado con las palabras homófonas se puede observar cuando se plantea la correcta utilización de Halla (de hallar)/haya/aya. La ausencia de recursos para la reflexión o la no presencia de normas nemotécnicas, implica que el hablante dude y por tanto, sea proclive al error.

Un último caso que tiene que ver con las palabras homófonas es el relacionado con los términos con $\mathrm{s} / \mathrm{x}$ ( $\mathrm{x}$ ante consonante). Este caso genera menos errores pero también es posible encontrar problemas en el hablante cuando intenta utilizar de manera óptima el término correcto para el contexto planteado de las siguientes parejas: Contesto (de contestar)/contexto, Espirar/expirar, Estirpelextirpe (de extirpar), Testo (de testar)/texto. Ante estas situaciones ayuda bastante que existan hablantes que pronuncien la /x/ como tal dentro del grupo fónico aunque los términos como contexto, expirar o extirpe no sean objeto de ello.

\section{Aproximación a una filosofía de didáctica de la lengua para ABORDAR LA HOMOFONÍA}

Los ejemplos anteriormente citados, nos muestran algunos de los problemas del hablante en el momento de utilizar la lengua española, pero obviamente únicamente son una muestra 
de las dificultades ya que hay otros términos que se relacionan con la situación homófona, que inducen al error o que han sido convertidos en errores por parte de los hablantes, éste es el caso de $a$ ver/haber, donde el importante uso que se realiza del segundo de los verbos, hace que se generalice el uso para ambas situaciones. Otro de los aspectos que tiene que ver en este error también tiene que ver con aspectos paralingüísticos, ya que la pronunciación que se hace, en ocasiones obvia la pausa necesaria en la primera de las situaciones. Si bien la pausa no es excesiva, en la composición a ver, sí existe y el hablante debería intentar realizar la distinción.

El hecho de que la homofonía no sea un fenómeno distintivo y significativo como sucede en lengua inglesa, no implica que no tenga que haber una intervención didáctica adecuada, residiendo gran parte de la responsabilidad en el docente que tiene que tener en cuenta la importancia de la reflexión sobre la lengua y la necesidad de apuntalar las bases gramaticales de la persona que aprende o usa frecuentemente la lengua española. Al respecto nos indica Álvarez-Angulo (2011: 270):

La mejor manera de hacerlo consiste en desentrañar, desde la Educación Primaria, el proceso que se sigue al escribir, de modo que se favorezca el análisis, la reflexión, la interiorización y el automatismo, con el fin de hacer a los alumnos competentes en la habilidad de escribir textos académicos. Esta función de la escritura se pone de manifiesto en las distintas ciencias que lo estudian: psicología cognitiva, pragmática, retórica, lingüística y didáctica de la escritura. Esto mismo lo atestigua el quehacer docente de maestros y profesores en su día a día profesional.

Si bien la propuesta de dicho profesor es parcial, ya que está centrada en el proceso escritor, sí está claro que sus palabras remiten a la rigurosidad en el estudio de lo lingüístico y sobre todo, a la puesta en práctica de la lengua que se aprende. Finalmente, la lengua y su aprendizaje suponen un proceso de uso constante en el que el usuario tiene que autorregularse con la inestimable ayuda que supone la interacción con el interlocutor, quien le puede informar de los posibles errores que comete. Retomamos ideas vertidas en secciones anteriores que tienen que ver con la formación del profesorado quien debe dominar la lengua (incluyendo todos los aspectos gramaticales) con el objeto de ser un referente claro para el hablante que se encuentra en proceso de aprendizaje.

Completan dicha aportación los términos usados por Rodríguez-Gonzalo (2012: 89) que nos dice:

en la actualidad, tanto en lenguas primeras como en lenguas extranjeras parece haber cierta coincidencia en que la atención a la forma (focus on form), es decir, un cierto tipo de gramática explícita, es ineludible en la didáctica de la lengua escrita desde los primeros niveles, en los usos elaborados de la lengua oral y en una didáctica de la lengua (de las lenguas) en contextos multilingües.

Con respecto de las palabras homófonas no podemos pensar en ellas para que se les aplique un enfoque didáctico que tenga que ver con lo memorístico, ya que sería un tanto estéril que la persona efectuase un ejercicio de memoria y generase un "banco de datos" con las diferentes parejas de palabras homófonas. Como hemos descrito, la inacción con el vocabulario motiva que se olviden, pierdan o simplemente no se tenga contacto con términos 
que se incluyen en el conjunto de palabras homófonas. Por consiguiente, parece claro que el profesorado en su intervención didáctica tiene que procurar que se generen atmósferas de aprendizaje donde los términos a estudiar fluyan de manera constante, es decir, se trata de expandir el vocabulario utilizado en el aula, y por ende, las estrategias de aprendizaje que se asocian al mismo. La implicación docente en este caso es mayor ya que tiene que procurar buscar recursos donde estén incluidos los términos que se desean trabajar en las secuencias didácticas, y en el caso de no encontrarlos debe ser el propio profesorado el que busque la manera de generar él los recursos con el fin de que aparezcan los términos y el alumnado tenga la oportunidad de interactuar con los mismos.

Pensemos en situaciones de uso de contraejemplos, si se le concede al alumnado la posibilidad de detectar errores y de justificar su presencia, éste estará trabajando con los aludidos términos homófonos y tomando conciencia de su presencia y utilización. El propio discurso del profesorado a la hora de explicar probando la capacidad del alumnado, poniéndolo en problemas e invitándole a distinguir entre determinados homófonos. Algunos juegos didácticos que posean definiciones, pueden incluir las dos posibilidades con la finalidad de que el alumnado realice la reflexión acerca de la lengua y tenga que elegir correctamente. Cuando nos referimos a atmósferas comunicativas, pretendemos que la lengua fluya en el aula, pero no por ello se prescinde de la reflexión gramatical ya que se procura que, la paradoja acerca de nuestro instrumento de comunicación que es estudiado mediante el propio uso de la lengua, tenga un sentido pleno.

La actividad didáctica clásica centrada en el debate, si éste es planteado para dilucidar si la presencia de homófonos en la lengua española es positiva o no, y qué sucedería si optásemos por la ortografía fonética, puede derivar en situaciones interesantes, ya que puede acontecer la paradoja referida a que el alumnado sea reticente al cambio, es decir a la eliminación de la norma actual, pese a que ésta es la que le plantea los dolores de cabeza originados por cometer errores. Es significativo que la evolución social haya derivado en errores que tienen que ver con los términos homófonos que tal vez pudiesen ser poco concebibles, pero este hecho no tiene que ver con la no estabilidad de la lengua sino con su vertiente dinámica, y en el uso de la lengua apreciamos las imprecisiones y errores de las personas. Obviamente en su grado correspondiente nativos y nuevos aprendices muestran cuáles son los errores significativos. Hemos comentado cómo la nueva ortografía de la Real Academia alude a ciertos errores que tienen que ver con los homófonos e incluye recomendaciones didácticas con el fin de no incurrir en el error. Sin duda, éste podría ser un estupendo recurso para el profesorado ya que haciendo uso de este texto proporcionado por la Academia podría mostrar al alumnado el desarrollo y definición de los términos y situaciones y comprobar cómo se resuelve. Al respecto, destacamos la utilidad como recurso didáctico de la página web de la RAE www.rae.es, que, dado su diseño e interactividad permite que alumnado y profesorado puedan resolver dudas y acudir a distintos diccionarios con la finalidad de realizar pertinentes aclaraciones sobre la lengua española y sobre todo, acerca de su uso.

A continuación reproducimos una historia en la que se han insertado una serie de términos homófonos que pueden derivar en ser contenido de distintas estrategias didácticas: 


\section{HISTORIA}

En la tenebrosa habitación el doctor dijo:

- Vacilo acerca de la naturaleza de la enfermedad del valido del rey. Dudo entre el accidente vascular y la posibilidad de un bacilo.

Tras la conversación convino con el servicio que la noticia no podía salir de palacio. Una vez que estaba fuera de la habitación, tuvo que bascular ante la llegada de un emisario que se encontraba muy ansioso.

- Cuéntame las noticias que llegan más allá de palacio- dijo el doctor.

El emisario le indicó:

- En el arroyo, cerca de una haya se sitúan unos traidores que han osado rayar el estandarte del reino.

- ¿Qué desecho humano podría intentar desprestigiar a la corona?

Caminaron hacia el lugar y solo pudieron escuchar el balido de una oveja. Habrán tomado un atajo y no será sencillo alcanzar a estos traidores- expresó el emisario. Y yendo detrás de él el doctor indicó que la vida del valido estaba próxima a su fin.

Con la esperanza de errar miró a su alrededor y tomando una de las espadas que yacía junto al rayado estandarte expresó:

- ¡ $i$ Hiendo esta espada en la tierra y prometo que no cesaré hasta encontrar a los culpables!

Y a continuación indicó:

- Voy a herrar mi caballo y partiré en búsqueda de ayuda hacia el castillo más próximo.

Al mismo tiempo desveló que, además de doctor, era caballero templario, nada menos que el maestre de la orden del Temple y recalcó:

- ¡Hatajo de malandrines, pronto acabaré con este modo de terrorismo!

Y así comenzó la andadura épica del caballero Hugo de Payens.

Ejemplos de posibles estrategias que se asocian a esta historia son las siguientes (dependerá del nivel de enseñanza -establecido éste de acuerdo con el MCERL, desde A1 hasta C2- que queramos trabajar y en función de éste, podremos acortar o extender la historia):

a) Dictado (con la consiguiente revisión comentada con la finalidad de reflexionar acerca de las dificultades)

b) Convertir el texto en una historia con huecos en blanco donde estén situados los homófonos y facilitar el listado de palabras para que el alumnado pueda incluirlas en los mencionados huecos.

c) Solicitar al alumnado que enumere los términos homófonos que ha detectado en el texto.

d) Pedir al alumnado que ordene los homófonos de mayor a menor dificultad según los haya detectado.

e) Generar una reflexión, mediante la organización de un debate donde el alumnado pueda expresar su parecer acerca de los homófonos y atribuya un valor determinado a los mismos. 
Estas actividades clásicas deben servir para poder establecer la reflexión acerca de la homofonía en la lengua española. Así, el hecho de que las palabras fluyan supondrá un beneficio para los usuarios nativos o extranjeros ya que, les permitirá aprender de sus errores $\mathrm{y}$, sobre todo, utilizar la lengua.

\section{Conclusiones}

Tras haber realizado el recorrido argumentativo a través de los diferentes epígrafes, en este apartado queremos apuntalar las ideas que hemos generado en esta aportación. Así, pensamos que el núcleo fundamental ha sido perfectamente explicado y planteado, ya que nuestra preocupación por los términos homófonos ha sido desplegada en las diferentes secciones y se ha mostrado la vigencia de las dificultades que las personas hablantes encuentran cuando se aproximan al uso de estos términos. Sin duda que esta situación se transpone explícitamente cuando nos referimos a la ortografía. Ésta, como referente gramatical de la lengua española muestra los aludidos problemas del hablante, ya que el descuido en el conocimiento de la lengua provoca que acontezcan las dudas y no sea posible mantener un rigor normativo en el momento de utilizar la lengua.

Por consiguiente, nuestra reflexión didáctica se orienta a incentivar al profesorado para que integre el uso de los homófonos y sobre todo, el acto reflexivo sobre los mismos, con la finalidad de que sean términos que el alumnado esté utilizando con cierta asiduidad y así no tenga que dudar a la hora de hacer uso de las mencionadas palabras homófonas. Al respecto presentar atmósferas de aprendizaje supone un avance significativo para el alumnado, es decir, que los discursos se hallen contextualizados -nos referimos en este punto al planteamiento comunicativo y activo a la hora de acometer la enseñanza de la lengua y la literatura- supone un estímulo más significativo para el estudiante que simplemente revisar normas ortográficas y gramaticales que se encuentren sin un contexto de referencia. No podemos olvidar en este entramado educativo que reclamamos la función de la lectura. Uno de los problemas recurrentes de los procesos de enseñanza y aprendizaje, tiene que ver con la pérdida del hábito lector. Realmente, en la misma se encuentra la fuente que nutre a la persona de palabras nuevas o que le permite estar en contacto con términos que conoce y por tanto, los reconoce reforzando su dominio sobre los mismos. Aunque el discurso oral también muestra palabras nuevas para el hablante, no le facilita su transposición al código escrito y es únicamente en el manejo de documentos, escritos y libros donde puede encontrar la solución a su duda relativa a cómo se escribe normativamente el término que usa. Entre los planteamientos lectores que pueden beneficiar a la persona, hay que mencionar que la lectura no se plantea como en el pasado sino que la tipología de usuarios ha sido modificada y ahora con los cambios sociales es más complicado plantear buenas prácticas lectoras. Sin embargo, consideramos que la lectura crítica es la que tiene que redundar en la mejora ortográfica de las personas ya que, además de incidir en la discusión del significado de lo leído, la misma tiene que incentivar la consideración estética de las formas lingüísticas y el valor de lo normativo.

Concluimos este texto indicando que en la actual configuración ortográfica de la lengua española, los homófonos siguen manteniendo su presencia normativa reflejada en el código escrito. En nuestro anhelo por el desarrollo de competencia en comunicación lingüística 
abogamos por la integración de buenas prácticas didácticas en relación con las palabras homófonas. Por esa razón, hemos querido destacar que, únicamente mediante la reflexión docente y la inclusión de los mismos en entornos comunicativos, es posible tener conciencia de este fenómeno lingüístico. Como hemos reseñado, la presencia de estos términos homófonos se corresponde con un contexto cultural determinado y no hacer caso a los mismos, o descuidarlos, redundará en la disminución de ese entramado cultural del que formamos parte.

\section{ReFERENCIAS BibliográficAS}

Álvarez-Angulo, T. (2011). "Revisar y reescribir textos académicos en la formación del profesorado", en Revista complutense de educación, 22: 269-294.

Bernstein, B. (1988a). Clases, códigos y control; I.- Estudios teóricos para una sociología del lenguaje. Madrid: Akal.

Bernstein, B. (1988b). Clases, códigos y control; II.- Hacia una teoría de las transmisiones educativas. Madrid: Akal.

Buenafuentes, C. y Sánchez, C. (2012). "Propuestas metodológicas para el tratamiento lexicográfico de la ortografía y la morfología a partir de las últimas obras académicas", en $L E A$ : Lingüistica Española actual, 34 (1): 87-114.

Callau, E. M. (2005). "Homógrafos y homófonos en español y en italiano", en RSEI, 3: 57-69.

Camps, A. (2006). La enseñanza de la ortografía. Barcelona: Graó.

Camps, A. (2009). "Actividad metalingüística y aprendizaje de la gramática: hacia un modelo de enseñanza basado en la actividad reflexiva", en Cultura y Educación: Revista de teoría, investigación y práctica, 21 (2): 199-214.

Carratalá, F. (1997). Manual de ortografía española: acentuación, léxico y ortografia. Madrid: Castalia.

Cassany, D. (2003). "La escritura electrónica”, en Revista Cultura y educación, 15 (3): 239251.

Cassany, D. (2006). Tras las líneas sobre lectura critica. La lectura crítica. Barcelona: Anagrama.

Cassany, D. (2012). "Leer y escribir literatura fuera del aula", en Aula de innovación educativa, 211: 49-53.

Consejo de Europa (2002). Marco común Europeo de Referencia para las Lenguas. Madrid: Anaya. Disponible en: http://cvc.cervantes.es/obref/marco (Último acceso: 02/05/2014).

Dalbor, J. B: (1980). Spanish Pronunciation: theory and practice. New York: Holt Winston.

De la Cruz, I. (1999). "Los juegos de palabras en la enseñanza de lenguas", en Encuentro. Revista de Investigación e Innovación en la clase de idiomas, 11: 58-65.

Gómez, A. (2007). "La ortografía del español y los géneros electrónicos", en Comunicar: Revista científica iberoamericana de comunicación y educación, 29: 157-164.

Gómez-Torrego, L. (2012). Ortografía fácil de la lengua española. Madrid: Espasa libros.

Guitart, J. (2004). Sonido y sentido: teoría y práctica de la pronunciación del español. Washington: Georgetown University Press.

Hammond, R. M. (2001). The sounds of Spanish: analysis and application. Somerville: Cascadilla Press.

Isla, P. (2012). "Evolución educativa: del pasado inmediato al entorno lector actual del nativo digital", en R. Sánchez y A. Mª. Ramos (Coords), Compromiso docente y realidad educativa. Retos para el maestro del siglo XXI. Madrid: Síntesis, 243-252. 
Lomas, C. (1999). Cómo enseñar a hacer cosas con las palabras. Teoría y práctica de la educación lingüística. Barcelona: Paidós.

Lomas, C. y Tusón, A. (2012). "Lengua, cultura y sociedad: una mirada sociolingüística a la enseñanza de la lengua", en Textos de didáctica de la lengua y la literatura, 60: 77-91.

Martín, $\mathrm{M}^{\mathrm{a}}$, T. (2003). "La precisión léxica: paronimios, homófonos y proformas", en. M. Rodríguez (coord.), Léxico, fraseología y falsos amigos. Madrid: SGEL, 115-140.

Morgan, T. (2009). Sonidos en contexto. New Haven: Yale University Press.

Pato, E. (2008). "Competencia, homofonía y pérdida de gramática: la historia de las preposiciones cabe y so en español", en Tinkuy: Boletín de investigación y debate, 10: 14-27.

Pérez-Esteve, P. y Zayas, F. (2007). Competencia en comunicación lingüística. Madrid: Alianza.

Real Academia Española (2010). Ortografia de la lengua española. Madrid: Espasa.

Rodríguez-Gonzalo, C. (2012). "La enseñanza de la gramática: las relaciones entre la reflexión y el uso lingüístico", en Revista iberoamericana de educación, 59: 87-118.

Sarmiento, R. (2010). "La nueva ortografía académica (2010). Historia de las reformas ortográficas", en Revista Cálamo FASPE, 57: 9-13.

Schwegler, A. y Kempf, J. (2007). Fonética y fonología españolas. New York: Wiley.

Techner, R. V. (2000). Camino oral. New York: McGraw Hill.

Unamuno, M. (2008) [1914]. Niebla. Madrid: Cátedra.

Waluch, E. y Vercher, E. (2007). "Propuesta metodológica y didáctica acerca del papel de los homónimos y parónimos entre español y polaco (aplicado al caso de estudiantes polacos en el aula de lengua española)", en J. Martí (coord.), Didáctica de la enseñanza para extranjeros: Actas del I Congreso Internacional de Lengua, Literatura y Cultura Española. Valencia: Onda, JMC, 475-491.

Widdowson, H. (1978). Teaching Language as Communication. Oxford: Oxford University Press.

Zayas, F. (1994). "Las actividades gramaticales desde una perspectiva textual", en A. Osoro y C. Lomas (coords.), El enfoque comunicativo en la enseñanza de la lengua. Barcelona: Paidós, 199-222. 